\title{
EL IDENTIFICADOR DE OBJETO DIGITAL(DOI) Y LA REVISTA MÉDICA PANACEA
}

\author{
THE DIGITAL OBJECT IDENTIFIER (DOI) AND THE PANACEA MEDICAL \\ JOURNAL
}

Jorge Ybaseta - Medina ${ }^{1,2}$.

1. Profesor del Departamento de Ciencias Quirúrgicas, de la Universidad Nacional San Luis Gonzaga de Ica, Perú.

2. Ginecólogo Obstetra del Hospital Santa María del Socorro. Ica, Perú.

doi: https://doi.org/10.35563/rmp.v8i2.1

EI DOI es un identificador permanente que es obligatorio se trata de un identificador de por vida que se apega al contenido de un objeto en línea en otras palabras se asignan números únicos personalizados a los PDF o HTML, audio, etc. (1) que son publicados en el Open Journal Systems (OJS) donde cada uno de estos objetos tiene su DOI haciendo posible que los usuarios puedan llegar a la fuente sin problemas, no importando si hay cambio de dirección electrónica de la revista o cambio de servidor puesto que el enlace DOI permanecerá asociado a la publicación científica, sin embargo si ocurriera cambio del localizador uniforme de recursos (URL) de la revista el sistema CrossRef logra automáticamente redirigir el DOI concreto a la nueva URL $(1,2)$.

Ahora que la Universidad Nacional San Luis Gonzaga está involucrada en la comunidad Crossref, los contenidos de la Revista Médica Panacea tienen la fortuna de estar conectados con la red global de investigación en línea esto gracias a la adquisición de la membresía se ha obtenido el prefijo del DOI (identificador del objeto digital) de Crossref conformado por los números: 10.35563 que aplicaremos a los contenidos de la revista creando de esta manera los DOls con el siguiente formato https://doi.org/[su prefijo] / [un sufijo de su elección], el sufijo está dado por la información contenida en la plataforma OJS que consigna las iniciales de la revista el volumen y número, un ejemplo del DOI asignado a una de nuestras comunicaciones científicas es https://doi.org/10.35563/rmp.v8i1.261

Es una satisfacción para toda nuestra organización el uso de los DOI Crossref porque permiten registrar el contenido, vincular y citar (2), es una ventaja exclusiva de importantes revistas científicas que manejan esta tecnología. 
REFERENCIA BIBLIOGRÁFICAS

1. Wood, C.C. Por qué Crossref existe y persiste [online]. SciELO en Perspectiva, 2018 [viewed 24 June 2019]. Available from: https://blog.scielo.org/es/2018/07/17/por-que-c rossref-existe-y-persiste/
2. Lammey Rachael. CrossRef developments and initiatives: an update on services for the scholarly publishing community from CrossRef. Sci Ed 2014;1(1):13-18. https://doi.org/10.6087/kcse.20 14.1.13

\section{PANACEA \\ UNIVERSIDAD NACIONAL SAN LUIS GONZAGA. ICA, PERU}

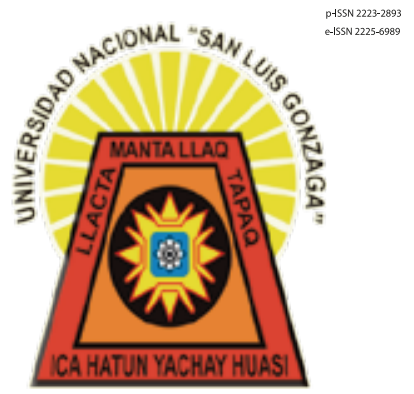

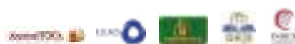

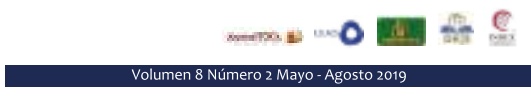

CITAR COMO

Ybaseta-Medina Jorge. El Identificador de Objeto Digital

(DOI) y la Revista Panacea. Rev méd panacea. 2019; 8(2):

56-57. doi: https://doi.org/10.35563/rmp.v8i2.269 